\title{
EDUCAÇÃO PROFISSIONAL E OS IDEAIS LIBERAIS PRESENTES NO PENSAMENTO EDUCACIONAL BRASILEIRO
}

\author{
Beatriz Lemos Stutz ${ }^{1}$ \\ Universidade Federal de Uberlândia- UFU \\ blstutz@gmail.com \\ Carlos Alberto Lucena ${ }^{2}$ \\ Universidade Federal de Uberlândia- UFU \\ carloslucena@centershop.com.br
}

\section{RESUMO:}

Este texto aborda a história da educação profissional em nosso país e sua estreita relação com os processos produtivos e os ideais liberais presentes no pensamento educacional brasileiro. A despeito da intensificação das reformas educacionais, a partir da primeira metade do século XX, permanecem ainda, na atualidade, marcas profundas do pensamento liberal nas decisões e práticas educacionais contemporâneas. $\mathrm{O}$ texto enfoca também a necessidade de descobrir-se o verdadeiro papel das escolas profissionais do ensino médio e aponta a incapacidade da educação de, por si só, produzir mudanças na sociedade, como queriam crer os intelectuais do Manifesto dos Pioneiros da Educação Nova.

Palavras-chave: história da educação, educação profissional, liberalismo, escolas técnicas.

\section{PROFESSIONAL EDUCATION AND THE LIBERAL IDEALS IN BRAZILIAN EDUCATIONAL THOUGHT}

\begin{abstract}
:
This text approaches the history of professional education in our country and its narrow relationship between the productive processes and the liberal ideals present in the Brazilian educational thought. In Spite the intensification of educational reforms since the first half of the 20th century, still remains in present time deep marks of the liberal thought in contemporaries educational practice and decisions. The text also focuses the necessity to discover the real involvement of those schools and shows the incapacity of education in changing the society by itselfs, as believed the intellectuals of Pioneers of the New Education Manifest.

Keywords: education history, professional education, liberalism, technical schools.
\end{abstract}

A história da educação profissional no Brasil guarda estreita relação com os processos produtivos ligados ao movimento de industrialização, que marcou o século XIX e às idéias liberais tão presentes no pensamento educacional brasileiro, cuja origem remonta dessa época, com expressivos representantes de nossa intelectualidade nacional.

O crescente processo de industrialização e urbanização, ao mesmo tempo em que exigia aumento na produção de manufaturas, gerava necessidades sociais em cujo cenário inscrevese a origem das escolas técnicas e profissionais. Com o paulatino avanço da população para 
os centros urbanos, movida por um lado pelo enfraquecimento da economia agrícola e da vida no campo e, por outro, pela ilusória oportunidade de trabalho assalariado pela expansão da produção e circulação de mercadorias, cria-se o aumento do contingente de uma camada populacional em condições precárias de vida e sem instrução, carente de meios que possibilitassem a sua sobrevivência. $\mathrm{O}$ ensino profissional brasileiro tem sua história marcada ao mesmo tempo por um caráter assistencialista e técnico. Uma viagem por seus caminhos nos mostra, no século XIX, práticas educacionais de congregações religiosas que, além das primeiras letras, ensinavam a crianças pobres e órfãs vários ofícios, dentre eles alfaiataria, sapataria e marcenaria, tendo oficinas e fábricas como mediadoras desse aprendizado $^{3}$.

Para Buffa e Nosella, o ensino profissional carrega um estigma assistencialista e, embora intelectuais a ele ligados tentem dissipá-lo, é fato que:

[...] a ciência, a técnica e a produção industrial modificam-se, que a pobreza e a riqueza assumem novos contornos, mas o ensino profissional, industrial e técnico (de nível médio) sempre foi e é, ainda hoje, um ensino voltado para os mais pobres. O mundo das artes liberais e o das artes mecânicas mudam e se complexificam mas nunca se misturam. O distanciamento entre eles permanece profundo. (BUFFA e NOSELLA, 1998, pp. 35-36)

As escolas profissionais de caráter técnico, voltadas para as necessidades da indústria, têm suas origens nos Liceus das Artes e Ofícios, destinados aos artesãos e seus filhos, com objetivo claro de proporcionar-lhes uma formação elementar em matemática e desenho industrial. O primeiro deles surgiu em 1858 no Rio de Janeiro. ${ }^{4}$ Essas escolas são consideradas importantes instituições, destinadas não apenas aos mais pobres, como também ao atendimento das necessidades da indústria. Constituíram-se, segundo Buffa e Nosella (1998, p. 39), "no divisor de águas entre as escolas para crianças pobres, prioritariamente assistencialistas, e escolas técnicas para a formação de profissionais que a indústria requeria."

Ao final do século XIX e primeira metade do século XX, a crise da economia cafeeira estimulou a criação de escolas para formação profissional de técnicos para a indústria, uma vez que eram vistas como alternativas para os filhos de um contingente de imigrantes que iam se fixar nas cidades, quer seja abrindo fábricas de pequeno porte, ou empregando-se nas indústrias.

A queda da Monarquia e a instalação da República no ano de 1889 são marcos a partir dos quais começam a delinear-se importantes aspectos que se revelarão como influências significativas na história da educação pública brasileira. A origem de nosso modelo educacional está no liberalismo, cujos fundamentos assentam-se na idéia de liberdade. $\mathrm{O}$ liberalismo não tem uma base unificada para seu surgimento, nascendo em consequiência de um longo processo de falta de liberdade e de um conjunto de circunstâncias e manifestações, entre os séculos XVI e XVIII, que acabam culminando com a perda de poder do rei, assim como da Igreja representada na figura do bispo. Nesse contexto, todos são iguais perante a Lei e a escola é considerada fundamental para que o indivíduo consiga viver na sociedade. Os ideais de uma sociedade igualitária, com escolas para todos, cujo objetivo seria preparar o indivíduo para a cidadania e para o trabalho passa a ser o mote da sociedade liberal. De acordo com os ideais liberais, a participação do Estado na vida das pessoas deve ser mínima, promovendo oportunidades iguais para que cada um possa trabalhar e sustentar-se mediante seu próprio esforço. Diante disso, havendo igualdade perante a Lei, com as mesmas oportunidades para todos, não só em relação à educação, mas na vida do sujeito de modo 
geral, há um estímulo e valorização do individualismo e o sucesso pessoal um depende do próprio sujeito. Apesar da defesa preconizada pela base filosófica liberal por uma educação humanista, como prioridade em relação à técnica, a história tem nos mostrado que à revelia da idéia de que a melhor escola é a que deve ser dada a todos, isso em verdade não ocorreu. $\mathrm{O}$ aumento do número de escolas ocasionou naturalmente a necessidade de pessoas para nelas trabalharem e não havendo o contingente de professores qualificados, o que se presencia, a partir daí, é a qualidade questionável do ensino. Entre uma idéia e sua concretização há um longo percurso e muitos percalços. Uma observação atenta dos princípios defendidos por intelectuais brasileiros e as práticas sociais, políticas e econômicas desse período aos dias atuais, mostra-nos uma práxis altamente contraditória à defesa de uma escola de qualidade e igual para todos.

\section{A educação e os ideais liberais presentes na intelectualidade brasileira}

Uma forte expressão do pensamento liberal, entre os intelectuais brasileiros, encontra-se na voz de José Veríssimo, cuja obra A educação nacional, publicada em 1890, é carregada de sentimento nacionalista, de amor à Pátria, com apelo para a construção e afirmação da identidade nacional no primeiro ano após a instauração da República. Para tal, propõe um projeto nacional em que a educação ocupe o primeiro lugar, sendo o meio certo e seguro ${ }^{5}$ para a formação do caráter do brasileiro, que em sua visão carecia de espírito de luta, de sacrifício, disciplina, altruísmo e dedicação ao trabalho. O currículo deveria estar perpassado por uma idéia moral superior. O referido autor faz também uma crítica contundente à educação para o trabalho, implícita no livro didático, que uma vez produzido por forte influência estrangeira, veiculava ensinamentos voltados para o desempenho de funções na indústria, não condizentes com a realidade nacional:

[...] uma das mais necessárias reformas é a do livro de leitura. Cumpre que ele seja brasileiro, que não é o mais importante, mas brasileiro pelos assuntos, [...] Que se ele nos der lições de coisas, não nos venha ensinar indústrias, ocupações e usos que nos são completamente alheios, postergando as manifestações, embora humildes por ora, da nossa atividade industrial. Que em vez de exclusivamente nos ensinarem o que é e como se prepara a lã ou o vidro, [...] e quais são os usos e empregos de madeiras e outros materiais que não possuímos, nos mostrem o que é e como se cultiva a borracha, quais seus empregos e qual a higiene profissional do seringueiro, [...] (VERÍSSIMO, 1985, p.55)

Percebe-se pelo discurso acima explicitado que o processo de industrialização no país caminhava timidamente. Daí a preocupação com a educação para o trabalho centrar-se em atividades ainda voltadas para a agricultura, pecuária e produtos artesanais de necessidades domésticas como, por exemplo, derivados do leite.

A preocupação com a educação e o trabalho como forma de alavancar $o$ desenvolvimento da nação avança de modo ainda mais contundente nos anos seguintes, tendo como seu forte representante Fernando Azevedo que, no período de 1927-1930, enquanto diretor-geral da Instrução Pública do Distrito Federal, leva a cabo uma reforma do ensino na capital brasileira que serviria de parâmetro para o ensino nacional, trazendo em seu bojo princípios escolanovistas. Trabalhou ativamente para a implementação de um programa de construções escolares, dentre as quais, surgiram duas escolas profissionais, 
consideradas na época de grande porte. Contudo, diante do conturbado panorama político brasileiro, houve no governo de Getúlio Vargas, no ano de 1931, a Reforma Francisco Campos, cuja prioridade dada aos ensinos universitário e secundário relega ao segundo plano o ensino primário. Nesse cenário, fruto da IV Conferência Nacional de Educação realizada em 1931, Fernando Azevedo encabeça um dos mais importantes documentos em defesa do que seria considerada a reconstrução educacional no Brasil. O Manifesto dos Pioneiros da Educação Nova, um trabalho elaborado a várias mãos, que contou com a participação efetiva de mais vinte e cinco renomados intelectuais brasileiros. Tal manifesto, publicado em 1932, embora não tenha se constituído em documento oficial, apresentou-se como clara insatisfação no que concerne aos rumos da educação no país e à cultura de descentralização educacional, instalada desde o Ato Adicional de 1834, em que a educação apresentava-se como iniciativa privada e dos Estados.

O Manifesto, à época também conservador por continuar com o propósito de uma escola para a elite, mostrou-se, enquanto proposta, como uma forma mais ampliada e igualitária que os modelos colocados anteriormente, dando um caráter orgânico para a educação, por pensá-la desde o início até sua terminalidade. Defendendo uma "escola comum e única" ${ }^{6}$, o princípio da escola para todos, com uma continuidade e articulação entre os diversos graus de ensino, faz uma crítica explícita à separação, até então existente, entre o ensino primário e profissional e o secundário e superior, ou seja, contra dois sistemas escolares paralelos que, na opinião de seus interlocutores, servia como instrumento de estratificação social. Com clara alusão ao ensino profissional, aponta o caráter falho da instrução pública no sentido de ser um canal de êxodo da juventude do campo para a cidade e da "produção para o parasitismo", enfatizando a necessidade de uma busca de soluções para os problemas educacionais da população rural e do trabalhador urbano:

É preciso, para reagir contra esses males, já tão lucidamente apontados, pôr em via de solução o problema educacional das massas rurais e do elemento trabalhador da cidade e dos centros industriais já pela extensão da escola do trabalho educativo e da escola do trabalho profissional, baseada no exercício normal do trabalho em cooperação, já pela adaptação crescente dessas escolas (primária e secundária profissional) às necessidades regionais e às profissões e indústrias dominantes no meio. (Manifesto dos Pioneiros da Educação Nova. In: GHIRALDELLI JR., 1990, p.68).

Em relação ainda a esse Manifesto, vale ressaltar seu importante papel na história da educação profissional brasileira, pois expressa uma defesa aos mecanismos de ascensão a níveis superiores de ensino pelos trabalhadores, impossibilitados de fazê-lo diante do dualismo educacional até então existente. Propõe a escola secundária unificada (dos 12 aos 18 anos), com objetivo de evitar-se a separação entre trabalhadores manuais e intelectuais, com uma formação geral comum por um período de três anos, a partir dos quais caberia ao aluno optar pela continuidade do curso voltado para disciplinas de cunho intelectual (humanidades, ciências físicas, matemáticas, químicas e biológicas) ou profissional, ligado à agricultura, mineração, pesca, produtos manufaturados e serviços (transporte, comunicação e comércio). Desse modo, contrário à Reforma Francisco Campos, seria possível ao aluno, após concluir o ensino secundário em qualquer uma dessas modalidades, prosseguir na carreira estudantil, pleiteando, caso o quisesse, seu ingresso no ensino superior. Contraditoriamente, embora apresente essa preocupação com uma educação igualitária, para além das classes, prioriza níveis educacionais para determinados segmentos, posicionandose a favor da meritocracia e de uma elite da qual deve fazer parte o professorado: 
[...], os melhores e os mais capazes, por seleção, devem formar o vértice de uma pirâmide de base imensa. [...] Essa seleção que se deve processar não "por diferenciação econômica", mas "pela diferenciação de todas as capacidades", favorecida pela educação, mediante ação biológica e funcional, não pode, [...] mas nem sequer realizar-se senão pela obra universitária que, elevando ao máximo o desenvolvimento dos indivíduos dentro de suas aptidões naturais e selecionando os mais capazes, lhes dá bastante força para exercer influencia efetiva na sociedade e afetar, dessa forma, a consciência social. (Manifesto dos Pioneiros da Educação Nova. In: GHIRALDELLI JR., 1990, p.72).

Sem dúvidas, tal Manifesto tornou-se um marco na história da educação brasileira enquanto instrumento político em defesa da escola pública, fundamentado no princípio da organização do ensino de forma articulada em seus diferentes níveis. Além disso, enfatiza o papel do Estado como órgão normatizador e fiscalizador das instituições e ações educativas, inclusive em relação à rede particular de ensino que, na visão desses intelectuais, era necessária, considerando-se a situação econômica do país que, segundo os quais, não teria capacidade de arcar com a gratuidade total do ensino. Prova de sua importância encontra-se também na influência que teve na elaboração do texto da Constituição de 1934 que colocou como atribuição da União fixar um plano nacional de educação, coordenando e fiscalizando a execução do ensino em todos os seus níveis.

Mais tarde, nos anos 40 do século XX, o então ministro da Educação e Saúde, Gustavo Capanema, promulga leis orgânicas do ensino, voltadas para a reforma do ensino médio e ensino técnico-profissional. ${ }^{8}$ Nesse momento, faz-se presente, mais do que nunca, a influência do pensamento liberal, sob a roupagem do Estado Novo, no governo Getúlio Vargas, acentuando-se o controle e fiscalização da educação pelo poder público, em defesa de um sistema de diretrizes morais, políticas e econômicas em favor de uma de Nação forte e organizada, de um sentimento de amor à Pátria, cuja concretização manifesta-se também no interesse de organização e controle da produção científica na área educacional, com a criação do Instituto Nacional de Pedagogia (INEP) em 1937. Vale ressaltar que a elaboração dessas leis acontece em um momento marcado por conflitos de ordem política e econômica, na era Getúlio Vargas, tendo também como pano de fundo a Grande Guerra.

O que mobilizou de fato as medidas no plano educacional nessa época? Qual significado real e intencionalidade das medidas que culminaram com os decretos-lei nesse período da história brasileira?

As palavras de Capanema, ao proferir discurso em defesa do Presidente da República, contra acusações de desvalorização humana com restrições da liberdade política, elevação do custo de vida e escravização do trabalhador, ilustram de forma clara um pensamento político no bojo do qual emergiram decisões na área da educação:

Não cabe, nas pretensões e nos limites de meu discurso, tratar desses problemas. Direi apenas que representa, sem dúvida, um erro de visão considerar, como termos negativos da política valorativa do homem, duas circunstâncias ocasionais, os limites do direito político e as dificuldades da economia popular, ambas decorrentes de nossa participação na guerra, ambas verificadas, pelo mesmo motivo, em países de adiantada cultura e notáveis pelo permanente esforço no sentido da valorização do ser humano. [...] Deixemos as sentenças depreciativas, mesmo quando proferidas com a mais elevada finalidade patriótica, pois elas, além de 
nos desprestigiarem perante o estrangeiro, podem pôr-nos em dúvida a respeito de nós mesmos. (CAPANEMA, 1985, p.189)

Ao considerar-se tal contexto, as Leis Orgânicas decorrentes da Reforma Capanema, que estabelecem as bases da organização e regime do ensino secundário, industrial, comercial, agrícola, normal e primário, no que diz respeito especificamente àquelas relacionadas ao ensino técnico-profissional, possuem aspectos importantes que merecem apontamento. Uma observação do Decreto-Lei referente ao Ensino Industrial nos permite visualizar como a educação nacional, tendo como representação as instituições educativas, não se desvencilha de interesses sóciopolítico-econômicos de seu tempo, mantendo estreita relação inclusive com um amplo contexto internacional (a exemplo das influências da Guerra sobre a economia, a política e a cultura de um país), tornando-se a compreensão de sua complexidade árdua tarefa. As Leis Orgânicas que modificam a dinâmica da educação profissional no Brasil nascem em um momento em que a crise internacional, vivenciada no ano de 1929, expandindo-se durante a Segunda Grande Guerra, acaba por influenciar o processo de industrialização no país com diminuição das importações e uma expansão do setor industrial que caracterizou o governo Vargas. A queda nas importações e o aumento de capital estrangeiro acarretaram problemas no que diz respeito à saída de divisas e gerou, por outro lado, a necessidade de ampliação do setor industrial na produção de bens de consumo, o que por sua vez criou a necessidade de trabalhadores especializados para a indústria. Aliado a isso, o conturbado cenário político brasileiro obrigou o governo, no Estado Novo, a buscar e assegurar a anuência da população aos seus ditames. Daí, os princípios inerentes às Leis Orgânicas aqui referidas serem voltados para a formação de pessoal especializado para a indústria, como também a tentativa de assegurar a reverência e o amor à Pátria via preparação principalmente dos jovens. A comprovação disso é a inserção na Lei Orgânica de Aprendizagem Industrial da obrigatoriedade de organização nas escolas de um centro cívico filiado à Juventude Brasileira9. A preparação profissional voltada aos interesses das empresas e como instrumento de mobilização da economia está claramente implícita no Art. $3^{\circ}$ do Capítulo I da referida Lei. Há ainda um objetivo claro, não apenas em relação aos jovens como também à habilitação profissional de adultos via cursos chamados Extraordinários, por meio dos quais, jovens e adultos não diplomados ou habilitados poderiam qualificar-se profissionalmente e permitir àqueles que já possuíam certificados em cursos de formação profissional ampliar seus conhecimentos ou desenvolver uma habilidade específica. A articulação dos estabelecimentos de ensino com empresas para realização estágios pelos alunos, sendo estes obrigatórios ou não, também corrobora a adequação da educação profissional aos objetivos destas. Esse ajustamento da educação profissional ao mercado de trabalho é explicitado por Mendes em seu estudo sobre políticas públicas e a trajetória do ensino profissionalizante de nível técnico no Brasil:

Encerrado um tempo em que prevaleceu a educação profissional para o ensino manufatureiro, inicia-se um novo período em que o ensino profissionalizante vai priorizar o ensino industrial, dimensionado aos propósitos de incentivar a industrialização pela formação sistemática da força de trabalho, revelando-se um esforço de ajustamento ao mercado de trabalho. (MENDES, 2005, p.42)

Vimos até aqui, como aponta Rubega (2000) que a escola nesse período era encarada como importante instrumento de reprodução das relações capitalistas dominantes e meio pelo qual se conseguiria maior participação na vida econômica e política da sociedade, via instrução do sujeito, tendo como consequiência maior produtividade e ascensão social. Nesse 
sentido, a educação era apresentada ideologicamente ao lado dos princípios de liberdade e igualdade em conformidade com o processo de industrialização.

A história da educação brasileira não está, como já foi dito, descolada da realidade social, política e econômica do país. Uma significativa influência de tais aspectos é percebida no longo percurso ocorrido entre a discussão, elaboração e implantação das Leis de Diretrizes e Bases da Educação Nacional. O processo para instalação da primeira LDB ${ }^{10}$ teve início no ano de 1947, quando o então ministro da Educação e Saúde, Clemente Mariani, instala a comissão encarregada de elaborá-la e o projeto é encaminhado à Câmara no ano seguinte. Daí ao seu desfecho final, passaram-se quatorze anos. Fruto de intensos e complexos debates que caracterizaram a implantação dessa Lei forças políticas buscavam firmar-se. Em um primeiro plano, Anísio Teixeira e Fernando Azevedo tiveram participação expressiva, não só na elaboração inicial da mesma, como também nos anos seguintes, quando do impasse provocado por um substitutivo apresentado por Carlos Lacerda, que entre outras questões, arrola igualdade de condições entre escolas oficiais e particulares. É interessante notar o forte envolvimento de Anísio Teixeira em relação a esse projeto, o qual pode ser constatado em uma de suas cartas enviadas ao amigo San Tiago Dantas ${ }^{11}$ em que chama atenção deste para aspectos importantes em relação à intencionalidade escondida em definições de termos que a seu ver, por serem ambíguos, possibilitariam interpretações em uma equivocada luta de interesses, dentre eles beneficiar escolas da rede privada. $\mathrm{O}$ ensino profissional foi também ponto de discussão quando abordava o fato de, até aquele momento, somente a Lei do Ensino Industrial haver sido aprovada porque o assunto não feria os interesses dos educadores privados, que não se dignavam a considerar esse gênero de ensino $^{12}$. Ao analisar este último aspecto, percebe-se claramente a frágil posição ocupada pela educação profissional na realidade nacional.

No período em que esteve atuando ativamente, não apenas como intelectual, com presença marcante no cenário educacional do país, mas também como homem público, concretamente envolvido na criação de instituições como a Universidade do Distrito Federal e o Instituto de Educação, identificado com o liberalismo igualitarista sob influência de Dewey, Anísio Teixeira deixou marcas expressivas, tanto na elaboração da Lei de Diretrizes e Bases quanto na questão dos direitos humanos. Foi defensor ardoroso da educação para a democracia e da escola como objetivo de formar o cidadão para exercê-la.

Como se vê, a regulamentação do ensino no Brasil tem suas bases fortemente assentadas na primeira metade do século XX, intensificando-se a partir daí mediante transformações expressivas na concepção que se tem de escola. Porém, marcas profundas do pensamento liberal permanecem no âmbito das decisões e práticas na área educacional contemporânea à medida que ainda se busca, mediante embates e conflitos educacionais, uma escola única, democrática, que assegure oportunidades iguais para todos. No que diz respeito ao ensino profissional isto não é diferente. $\mathrm{O}$ que se via e aquilo pelo qual intelectuais e políticos levavam a cabo intermináveis discussões, com contradições nem sempre aparentes, continua alinhavando os capítulos referentes à história da educação. Mesmo com as futuras $\operatorname{LDBs}^{13}$, as instituições de ensino voltadas para a educação profissional vivenciaram processos de mudança que não foram, contudo, suficientes para solucionar o dualismo a ela inerente. Dualismo este em que sempre esteve em jogo a função social da escola enquanto instrumento para amenizar as dificuldades de acesso à educação pelos sujeitos ditos "excluídos", e uma escola que preparando esse mesmo sujeito para o trabalho estaria contribuindo para o aumento da produtividade e desenvolvimento econômico. Nos anos 70 do século XX, com a LDB nº 5692/71, as escolas de Ensino Médio viram-se obrigadas a oferecer cursos profissionalizantes em todo o território nacional. Perfeito fracasso, devido à impossibilidade de o Estado arcar com os custos necessários. Dessa forma, seu caráter 
compulsório é revogado em 1982. Nesse período, a educação foi alvo de sérias críticas as quais, segundo Saviani (2004, p.50), a concepção produtivista da educação, subordinada ao desenvolvimento econômico, estende-se ao longo da década de 1980, resistindo aos ataques a ela dirigidos durante esses anos, vindo a ser acionada como um instrumento de ajustamento da educação às demandas do mercado numa economia globalizada centrada na tão decantada sociedade do conhecimento.

Pela Lei de Diretrizes e Bases da Educação n. 9394/96, a educação profissional, em articulação com o ensino regular ou estratégias de educação continuada, passa a ser integrada às diferentes formas de educação, ao trabalho, à ciência e à tecnologia, conduzindo ao permanente desenvolvimento de aptidões para a vida. Além disso, delineia claramente, nos Princípios e Fins da Educação Nacional, aspectos inerentes ao Liberalismo, tais como liberdade de pensamento, pluralismo de idéias e concepções pedagógicas, gestão democrática do ensino público e vinculação entre escola, trabalho e práticas sociais. Texto este, diferente do enunciado da LDB anterior (Lei $n^{\circ}$. 5692/71), cuja parte inicial do documento resume-se a apontar como objetivo do então ensino de $1^{\circ}$ e $2^{\circ}$ graus proporcionar ao educando a formação necessária ao desenvolvimento de suas potencialidades como elemento de auto-realização qualificação para o trabalho e exercício consciente da cidadania.

Ao que parece, nem os avanços científico-tecnológicos, nem os processos de transformação das relações produtivas foram capazes de apresentar saídas concretas para a solução dos dilemas existentes na educação, principalmente no que concerne ao ensino profissional, uma vez que a problemática explícita na Lei $\mathrm{n}^{\circ}$. 10.172 , de 09 de janeiro de 2001, que aprova o Plano Nacional de Educação, tanto quanto as contradições presentes nas LDBs e práticas educativas, refere-se à dificuldade de alunos que pleiteiam vagas nas escolas técnicas federais em conseguirem ser aprovados em seu processo seletivo (segundo este documento, por constituírem-se em estabelecimentos de ensino de alta qualidade e de oferta restrita), sendo as vagas, em grande parte, preenchidas por jovens de maior renda. Contudo, surge aí uma contradição que merece ser pesquisada e melhor esclarecida. Os jovens trabalhadores são realmente os que mais necessitam de uma escola que visa, em primeiro plano, à especialização profissional? Caso isso se confirme, de que tipo de formação esses jovens realmente necessitam?

Manacorda (2004, p.350), ao abordar as tendências e dificuldades, em vários países, para encontrar soluções efetivas para a educação secundária, na segunda metade do século XX lança uma questão que ainda permanece viva: $O$ que isso significa a não ser o problema comum de resolver a relação entre escolas desinteressadas e escolas profissionais, aspecto interno das relações mais gerais entre cultura e profissão, instrução e trabalho?

Dilema de difícil solução diante da complexidade que se esconde nas entrelinhas das relações sociopolítico-econômicas presentes hoje em nossa sociedade. Ao que tudo indica, parece que ainda continuaremos a trilhar um longo caminho até começarmos concretamente a delinear respostas com assertividade. Além disso, outra intricada questão, o princípio da terminalidade, continua sendo um ponto nodal, de difícil solução no âmbito da educação profissional. Aqueles que a teriam como finalidade última, enquanto nível de formação, não estão na escola, pois, buscam a cada dia meios para sua subsistência, quer seja nas indústrias, no comércio ou nas ruas. Soma-se a isso a barreira representada pela maioria dos processos seletivos das instituições escolares. E ainda há aqueles que nela ingressam, representados por um percentual significativo de estudantes de classe média, quando não estão à espera de aprovação em exames vestibulares para o ensino superior, vêem nos cursos profissionalizantes uma forma de adquirir recursos no mercado de trabalho, após seu 
término, para arcar futuramente com os custos de um curso de graduação, lugar onde realmente desejam estar.

\section{Considerações Finais}

Não há dúvidas de que a sociedade atual enfrenta um grande desafio: a convicção em relação à escola como meio de acesso ao emprego e conseqüentemente como forma de ascensão social já não é mais a mesma. Ao contrário, o que se vê é uma desconstrução dessa ideação, ao longo dos anos, diante das transformações cada vez mais aceleradas nos vários segmentos da economia e modos de produção, da política, da ciência e das relações sociais. O homem, atônito, tenta agarrar-se à educação como saída. Velhos dilemas em nova roupagem. A resposta não está apenas na educação, na política ou no indivíduo, como muitas vezes se quer fazer acreditar. A dificuldade em encontrá-la mora justamente na compreensão e mudança dessa complexa rede tecida entre todos esses aspectos. Enquanto isso devemos descobrir o que cabe a cada segmento envolvido na área educacional. Em relação ao ensino profissional, não se trata de negá-lo ou considerá-lo um caso secundário, de menor valor como tem sido encarado até os dias atuais. Embora as questões acima explicitadas nos coloquem diante de um quebra-cabeças, é necessário esclarecer qual o verdadeiro papel das escolas voltadas para a formação profissional. Pesquisas nessa área que dêem visibilidade ao destino de alunos que por elas passaram, talvez possam nos mostrar, com maior clareza, qual caminho seguir. Com certeza, tais escolas, queiramos ou não, têm um importante papel social não para a classe média, como os fatos nos têm mostrado, mas para aqueles que verdadeiramente encontram nessas instituições seu ponto de partida. Isso pode ser ilustrado pela perspectiva de avanço, tal como foi apontada por uma técnica em enfermagem, ao falar sobre o que significou para ela fazer o curso, em pesquisa realizada sobre o perfil desse profissional no município de Uberlândia:

\footnotetext{
$\mathrm{Eu}$ acho que qualquer pessoa que se especializa em qualquer coisa, se torna mais gente. Se torna mais humano. Quem tem o conhecimento, tem o domínio [...] Fica diferente a maneira de eu conduzir acho que até a minha casa [...] E além da perspectiva. Todo mundo que faz alguma coisa tem uma perspectiva de vida. (STUTZ, 1998, p. 153)
}

Porém, a mesma profissional toca no ponto nevrálgico a que nos referimos anteriormente, que confirma que a escola por si só não é capaz de mudar a sociedade como queriam crer os intelectuais do Manifesto dos Pioneiros:

Eu ainda acho que a escola dá uma base sólida. E o mercado, ele exige essa base sólida e te contrata como auxiliar [...] então o mercado é meio ingrato nessa situação do técnico. (STUTZ, 1998, p. 153).

Diante do aqui exposto, percebe-se na história da educação que os ideais liberais marcaram forte presença e ainda estão nas entrelinhas das deliberações que dizem respeito à vida da educação no país. E, embora estejam sendo desmistificados, os intelectuais que os representaram tiveram importante papel em sua estruturação e organização atual. 


\section{Referências}

BRASIL. Lei $n^{\circ}$. 9.394, de 20 de dezembro de 1996. Estabelece as Diretrizes e Bases da Educação Nacional. Disponível em: http://www.educacaoonline.pro.br. Acesso em 25 de nov. 2007.

Lei $n^{\circ} .10 .172$, de 09 de janeiro de 2001. Aprova o Plano Nacional de Educação e dá outras providências. Disponível em: http://www.planalto.gov.br. Acesso em 27 de nov. 2007.

BUFFA, Ester; NOSELlA, Paolo. A Escola Profissional de São Carlos. São Carlos: EdUFSCar, 1998.

CAPANEMA, Gustavo. Capanema e a educação brasileira. Revista Brasileira de Estudos Pedagógicos, Brasília, 66(153), p.187-200, maio/ago., 1985.

CUNHA, Luiz Antônio. O ensino industrial-manufatureiro no Brasil. Revista Brasileira de Educação, no. 14, p. 89- 107, mai/jun/jul/ago, 2000.

MANACORDA, Mario Alighiero. História da Educação: da Antiguidade aos nossos dias. 11ªed., São Paulo: Cortez, 2004.

Manifesto dos Pioneiros da Educação Nova. In: GHIRALDELLI JR., Paulo. História da Educação. São Paulo: Cortez, 1990, p. 54- 78.

MENDES, Laudenir Otávio. Políticas públicas e a pedagogia das competências na educação profissional: a trajetória do ensino profissionalizante de nível técnico no Brasil e no Estado de São Paulo. Campinas, SP Tese (doutorado) - Faculdade de Educação, Universidade Estadual de Campinas, Campinas, 2005.

RUBEGA, Cristina Cimarelli Caballero. A reforma da educação profissional de nível médio e a formação do técnico em química: retrospectiva e perspectivas de uma profissão. Campinas, SP Tese (doutorado) - Faculdade de Educação, Universidade Estadual de Campinas, Campinas, 2000.

SAVIANI, Dermeval. et al. (2004). O legado educacional do século XX no Brasil. Campinas: Autores Associados.

STUTZ, Beatriz Lemos. Técnico em Enfermagem: o perfil traçado por profissionais da área no município de Uberlândia, nos anos 90. Dissertação (mestrado) - Faculdade de Educação, Universidade Federal de Uberlândia, Uberlândia, 1998.

TEIXEIRA, Anísio. Carta a San Tiago Dantas, 21 de jul. 1959, Rio de Janeiro, Biblioteca Virtual Anísio Teixeira. Disponível em: http://www.prossiga.br/anisioteixeira. Acesso em: 28 nov. 2007.

VERÍSSIMO, José. A educação nacional. $3^{\text {a }}$ ed., Porto Alegre: Mercado Aberto, 1985. 
Notas:

${ }^{1}$ Professora da Escola Técnica de Saúde da Universidade Federal de Uberlândia. Doutoranda em Educação pela FACED/UFU.

${ }^{2}$ Doutor em Filosofia e História da Educação. Professor do Programa de Pós-Graduação em Educação da Universidade Federal de Uberlândia. Pesquisador do Programa Mineiro de Pesquisadores da FAPEMIG.

${ }^{3}$ Buffa, Ester; Nosella, Paolo. 1998, p.36.

${ }^{4}$ Cunha, Luiz Antônio. 2000, p. 92.

${ }^{5}$ Veríssimo, José. 1985, p.43.

${ }^{6}$ Manifesto dos Pioneiros da Educação Nova. In: Ghiraldelli Jr., 1990, p.62.

${ }^{7}$ Idem, p.68

${ }^{8}$ Decreto-Lei N ${ }^{\circ} .4 .073$ - de 30 de janeiro de 1942 - Lei Orgânica do Ensino Industrial

Decreto-Lei No . 6141- de 28 de dezembro de 1943 - Lei Orgânica do Ensino Comercial

${ }^{9}$ A Juventude Brasileira foi instituída no governo Vargas com vistas à preparação física, moral e espiritual de crianças e jovens (entre 8 e 18 anos) com uma orientação ideológica de acordo com a realidade política do país.

${ }^{10}$ Lei no ${ }^{\circ}$ 4.024, de 20 de dezembro de 1961- Fixa as Diretrizes e Bases da Educação Nacional.

${ }^{11}$ Teixeira, Anísio. Carta a San Tiago Dantas, Rio de Janeiro, 21 jul. 1959.

12 idem

${ }^{13}$ Lei $^{\circ}$. 5692/71 e Lei ${ }^{\circ} .9394 / 96$

Artigo recebido em: 13/02/2009

Aprovado em: 8/10/2009 